relationship such majority and minority views may bear to the complex and sometimes speculative issues of medical research. Insubstantial minorities have a way of being right in the end. According to the letter, also, the M.R.C.'s head office has agreed that one member of the committee of the A.S.T.M.S. Carshalton Research Branch should be present at "the meeting with the selection committee."

If an organization is going to appoint a director of a unit, nobody should object to the appointing committee seeking the advice of members of the unit's staff about its future direction. Nor should members of the staff feel reluctant to express their opinion, for they may have valuable experience on which to draw. But the intrusion of a trade union to get these views formulated and represented on matters well outside the traditional services of trade unions should make professional people pause. It will certainly make many trade unionists do so. Designed as they are to protect the terms and conditions of work of their members, trade unions are ill suited to organize the formulation of staff views on the future scientific policy of an M.R.C. unit. The B.M.A.'s own view in these circumstances was limited to stating that, if a non-medical director was appointed to the unit, the setting up of a separate clinical unit was worth serious consideration.

The acquiescence of the Medical Research Council in this procedure has caused anxiety among some members of its staff who know of it. Certainly it is puzzling to those who recall the independent stand the M.R.C. has so often taken to safeguard its research policies. Whether future appointments are to invite the same type of scrutiny remains to be seen. If they do, research workers may think twice before submitting themselves to it.

\section{Haemoptysis in Cystic Fibrosis}

Cystic fibrosis has been considered as a disease of infancy and early childhood, but with earlier diagnosis and improved treatment some patients now reach adult life. Complications in the older patients are being reported, of which the most recent is massive haemoptysis. ${ }^{1}$ Small haemoptysis, or blood streaking of sputum, has previously been reported. ${ }^{2-4}$ Bleeding is most likely when patients have either gross disease throughout the lungs or a local area of severe bronchiectasis, but it can complicate mild disease, forceful coughing, or severe exercise, though not commonly. Haemoptysis may be associated with an acute respiratory infection, but it is as likely to occur without any recognizable cause. In some patients aerosol inhalations of saline, acetylcysteine, and occasionally antibiotics cause paroxysms of coughing, which may be the cause of the bleeding.

In cystic fibrosis blood streaking of sputum seldom occurs below the age of 10 years. The report from Boston ${ }^{1}$ concerns 19 patients with massive haemoptysis of an estimated minimum blood loss of $500 \mathrm{ml}$. Fourteen of these patients were over the age of 15 and only one was under 12. In Great Britain the number of patients with cystic fibrosis over the age of 15 is at present small. Life tables published in $1966^{5}$ showed that by the end of the 15th year of life three-quarters of patients with cystic fibrosis had died. These tables covered 20 years and 367 patients. Considerable improvement in prognosis is reported in the last few years, ${ }^{6}$ and now a $70 \%$ survival at age 15 might be expected. Therefore the problem of massive haemoptysis may increase in the future.
The nature of the lesion causing haemoptysis is not clearly known. The gross pathological lesion in a series of children was bronchiectasis, but detailed studies of the pulmonary vessels were not reported. ${ }^{78}$ Lung tissue is probably destroyed by infection and then the blood vessels eroded. Injection studies show an increase in vascularity of the bronchial circulation in areas of bronchiectasis, ${ }^{910}$ and bronchopulmonary arterial anastomoses ${ }^{11}$ have been demonstrated. Catheter studies of patients with advanced disease show that some have pulmonary hypertension. ${ }^{12} 13$ These factors may all tend to make bleeding profuse and prolonged once it has started. There is also some evidence that the development of pulmonary arteries may be abnormal. ${ }^{14}$ Therefore perfusion of some areas of lung may not be normal, and this, associated with the spread of endobronchial infection, could lead to bronchiectasis.

Management of the patient with haemoptysis chiefly depends on the severity of the bleed. Since exacerbation of infection may be a precipitating factor, antibiotic therapy is advisable. The presence of an abnormal bleeding tendency should be looked for; an increased prothrombin time or low platelet count is sometimes found in association with liver dysfunction. Vitamin $\mathrm{K}$ is administered if indi-ated.

The patient should be kept active unless the bleed is severe. Hard coughing is discouraged, but postural drainage and physiotherapy should be continued unless they increase the bleeding. With severe haemoptysis admission to hospital is necessary. Sedation may be needed to allay alarm, but suppression of the cough reflex should be avoided. The indications for blood transfusion will be the same as in any haemorrhage. Most of these patients will be in the terminal phase of chronic respiratory disease, and surgical treatment will not be tolerated. Attempts to locate the bleeding by bronchoscopy are not indicated. The minority of patients who have severe bleeding with a localized area of disease on $x$-ray and reasonable pulmonary reserve may be examined by bronchoscopy when the bleeding is abating to determine if the local disease is the site of the bleed. In these patients there may be a place for surgical resection of the lesion after recovery from the haemorrhage. Though surgical treatment should be considered, the danger exists that the further life experience may be little more than attenuated death, so that a critical assessment of the whole situation must be made.

Holsclam, D. S., Grand, R. J., and Shwachman, H., Fourna! of Pediatrics, $1970,76,829$.

2 Schwachman, H., in Disorders of the Respiratory Tract, ed. E. L. Kendig, jun., p. 548. Philadelphia, Saunders, 1967.

Ores, C. N., and Baker, D. C., jun., American Review of Respiratory Diseases, 1969, 99, 790.

- Doershuk, C. F., and Matthews, L. W., in Ambulatory Pediatrics, ed M. Green and R. J. Haggerty. Philadelphia, Saunders, 1968.

- Mantle, D. J., and Norman, A. P., British Medical fournal, 1966, 2, 1238

- Norman, A. P., in Proceedings of the 5th International Cystic Fibrosis Conference, ed. D. Lawson, p. 331. London, Cystic Fibrosis Research Conference, ed.
Trust, 1969.

'Bodian, M. L., in Fibrocystic Disease of the Pancreas. New York, Grune and Stratton, 1953.

" Andersen, D. H., Annals of the New York Academy of Sciences, 1962, 93, 500 .

9 Wentworth, P., Gough, J., and Wentworth, J. E., Thorax, 1968, 23, 582.

10 Mack, J. F., Moss, A. J., Harper, W. W., and O'Loughlin, B. J., British Fournal of Radiology, 1965, 38, 422.

11 Moss, A. J., et al., Pediatrics, 1968, 41, 438.

12 Goldring, R. M., et al., fournal of Pediatrics, 1964, 65, 501.

13 Moss, A. J., Harper, W. H., Dooley, R. R., Murray, J. F., and Mack, J. F., Fournal of Pediatrics, 1965, 67, 797.

is Davies, G., in Proceedings of the 5th International Cystic Fibrosis Conference, ed. D. Lawson, p. 350 . London, Cystic Fibrosis Trust, 1969 